\title{
"No estamos de acuerdo con el titulo". Escribir un libro con estudiantes universitarios interculturales
}

"We do Not Agree on the Title": Writing a Book with Intercultural Students

Artículo de investigación | Research article

Fecha de recepción: 20 de junio de 2019 Fecha de aceptación: 07 de febrero de 2020 Fecha de disponibilidad en línea: septiembre de 2020

doi: 10.11144/Javeriana.m13.neat

María Verónica Di Caudo-Villoslada verodicaudo@hotmail.com Universidad Católica Argentina, Argentina (D) ORCID: https://orcid.org/0000-0002-2886-333X

Para citar este artículo | To cite this article Di Caudo-Villoslada, M. V. (2020). "No estamos de acuerdo con el título". Escribir un libro con estudiantes universitarios interculturales. magis, Revista Internacional de Investigación en Educación, 13, 1-27. doi: 10.11144/Javeriana.m13.neat 


\title{
Resumen
}

Este artículo de investigación presenta el proceso de investigación, escritura y publicación de un libro por parte de un grupo de investigadores conformado por estudiantes universitarios y una académica. El propósito es mostrar cómo el trabajo colaborativo con los estudiantes permitió descubrir los sentidos, los significados y las prácticas que los convertían en estudiantes interculturales y no solo en beneficiarios de políticas y programas inclusivos. La experiencia se llevó a cabo en el contexto de una investigación etnográfica sobre los procesos de inclusión de jóvenes en los estudios superiores, realizada en Quito, Ecuador, entre el 2013 y el 2016.

\section{Palabras clave}

Educación superior; Ecuador; etnografía; política educacional

\begin{abstract}
This article presents the process of research, writing and publication of a book written by a group of researchers comprised by university students and one academic. The purpose is to show how the collaborative work with the students allowed to discover the sense, meaning and practices that made them "intercultural students" and not only "beneficiaries" of policies and programs of inclusion. The experience was performed in the context of an ethnographic research about the inclusion processes of young people in post-secondary studies, carried out in Quito, Ecuador, between 2013 and 2016.
\end{abstract}

\section{Keywords}

Higher education; Ecuador; ethnography; educational policy 
Descripción del artículo | Article description

Este artículo de investigación se deriva de la tesis doctoral

"Somos estudiantes interculturales". Un estudio etnográfico

sobre sentidos y producciones de la inclusión en una

universidad salesiana en Ecuador, presentada en la

Universidad Nacional de Córdoba, Argentina.

\section{Introducción}

Una tarde que estaba conversando con Mary ${ }^{1}$ en la residencia, me explicó:

Yo soy la única shuar ${ }^{2}$ en la universidad, y todos tienen un pensamiento que es todo selva donde estamos y vivimos, y no es así. Piensan que andamos con taparrabos, la gente es prejuiciosa y racista. La gente te pregunta de dónde eres y se te quedan mirando mal. Yo les digo: iNo es imposible que los shuar lleguen a la universidad! (cuaderno de campo, octubre de 2013).

Ella no era la única joven becada de este pueblo indígena amazónico que estaba comenzando los estudios de una carrera profesional. Algunos jóvenes migraban desde sus comunidades rurales a la ciudad con el objetivo de estudiar en la universidad; especialmente desde que Ecuador había sido declarado constitucionalmente como intercultural y plurinacional en el 2008.

Muchos Gobiernos latinoamericanos, a partir de los 90 y con mayor énfasis durante la última década, han apuntado al reconocimiento identitario y a la promoción de la inclusión intercultural. Lo han hecho a través de políticas públicas y programas innovadores como estrategias vinculadas a condiciones de equidad para el acceso, la permanencia y la culminación de los estudios mediante gratuidad, becas, cuotas y diferentes mecanismos de acción afirmativa y discriminación positiva (Aponte-Hernández, 2008; Castro-Freitas \& Harder, 2013; Chiroleu, 2009; 2013; Dietz, 2012; García \& Paladino, 2007; 2011; Miranda, 2013; 2015; Ossola, 2010; 2013; Ossola \& Paladino, 2016; Rosso, 2016).

1 Utilizo seudónimos en los nombres propios para resguardar la identidad de los jóvenes.

2 Los shuar son el pueblo indígena amazónico más numeroso. Habitan en las selvas de Perú y Ecuador. Los españoles y criollos los denominaron jíbaros. 
A mediados del 2013, interesada en la temática de la interculturalidad, comencé a estudiar los procesos que derivaron de la implementación de un programa de inclusión intercultural para acrecentar las oportunidades de acceso, permanencia y profesionalización de indígenas y afroecuatorianos ${ }^{3}$ a carreras convencionales. Advertí que no resultaba suficiente con analizar las políticas inclusivas destinadas a estos grupos de estudiantes y que era necesario comprender la inclusión intercultural, partiendo de lo que hacían, decían y pensaban los distintos actores y grupos involucrados.

En este trabajo me focalizo en un proyecto organizado por la congregación salesiana ${ }^{4}$ y la Universidad Politécnica Salesiana a través de becas de estudio, alimentación y hospedaje en una residencia estudiantil. Residencia y universidad (ambas dependían de la misma institución eclesial) sostenían este proyecto a partir de un convenio que habían establecido. La Universidad Salesiana contaba con la Carrera de Educación Intercultural Bilingüe, que formaba profesionales en educación, especialmente maestros indígenas desde 1994. Lo novedoso eran las políticas educativas destinadas a la inclusión de jóvenes indígenas en distintas carreras de la universidad, como Ingeniería, Comunicación y Psicología, entre muchas otras.

El trabajo de campo incluyó, además de las estrategias habituales usadas en el enfoque etnográfico, una experiencia de talleres con jóvenes que se habían trasladado de sus comunidades rurales a la ciudad para vivir en una residencia estudiantil y estudiar en la universidad. Mary pertenecía al grupo que había obtenido una beca para estudiar en Quito.

Este artículo tiene el objetivo de mostrar cómo el trabajo colaborativo con un grupo de estudiantes permitió descubrir los sentidos, los significados y las prácticas que los convertían en estudiantes interculturales y no solo en "beneficiarios" de políticas y programas inclusivos. En el trabajo colaborativo con esos Otros que la investigadora pretendía estudiar, se dieron descubrimientos a los que no se hubiera llegado sin el proceso compartido con este grupo de jóvenes estudiantes universitarios. Los diálogos, los encuentros y los desencuentros, las interacciones y las formas diferentes de pensar (y pensarnos) fueron las que evidenciaron el sentido de la inclusión para los sujetos que eran los "destinatarios" de este tipo de política.

3 Utilizo el masculino genérico para referirme tanto a estudiantes mujeres como a estudiantes varones con el propósito de facilitar la lectura.

4 Los Salesianos de Don Bosco son una congregación religiosa perteneciente a la Iglesia católica, fundada por san Juan Bosco el 18 de diciembre de 1859, en Turín. 
A continuación, presento la contextualización de la investigación y algunas discusiones básicas que encuadran teóricamente el estudio. Luego, describo de forma general los talleres que realizamos con los jóvenes y relato un episodio que definió el título del libro coproducido. En los apartados siguientes cuento cómo se fueron realizando las tareas que prepararon su publicación y presentación pública en la universidad. Finalmente, destaco cómo el diálogo de reflexividades entre jóvenes e investigadora permitió profundizar los sentidos, las diferencias y las relaciones entre inclusión e interculturalidad, y cierro con unas breves conclusiones del proceso de prácticas colaborativas que acá pongo en consideración y que pueden convertirse en intersticios de enunciación intercultural.

\section{Contextualización del campo etnográfico y delimitaciones teóricas}

Ecuador es el cuarto país más pequeño del subcontinente, pero es el más densamente poblado de América del Sur y el décimo país más poblado de América, con la existencia de 18 pueblos indígenas y 14 nacionalidades reconocidas por el Consejo Nacional de Desarrollo de las Nacionalidades y Pueblos del Ecuador. Desde el 2008, el término interculturalidad (junto al de buen vivir o sumak kawsay, recogido por la Constitución gracias a campañas de la Confederación de Nacionalidades Indígenas del Ecuador y

de la Corporación de Desarrollo Afroecuatoriano) era de uso común entre personas indígenas y no indígenas, en discursos políticos, educativos, sociales y turísticos; emergía en slogans de propaganda en la vía pública, en libros escolares, en títulos de tesis, cursos y eventos académicos. Ecuador se mostraba al mundo como el primer país intercultural reconocido en su carta magna. El discurso sobre la interculturalidad avanzaba en variados ámbitos de la vida social, acompañado de una importante inversión en diversas políticas públicas enfocadas a la promoción de lo intercultural, como era mencionado en términos nativos en variadas ocasiones y contextos.

Vale la pena destacar un elemento muy significativo para el contexto de esta investigación. Mientras que en algunos países la interculturalidad había sido un concepto introducido por las políticas públicas internacionales y nacionales, y hasta por ONG, en el Ecuador la presencia del movimiento indígena y afroecuatoriano con sus organizaciones actuaron con miras a obtener reivindicaciones políticas, económicas y culturales, dotando de significado propio a la interculturalidad (Altmann, 2013; Maldonado, 2011). Desde la perspectiva del movimiento indígena, la interculturalidad tenía un profundo sentido político, exigía el reconocimiento simultáneo como pueblos diferentes y como actores nacionales y ligaba la educación al 
cambio social, haciendo de las instituciones educativas un escenario crítico en el cual se pueden producir relaciones étnicas no jerárquicas ni discriminatorias. Intelectuales, activistas y grupos e individuos pertenecientes a movimientos indígenas concordaban en que la interculturalidad era un proyecto de transformación de la sociedad necesario para poder transformar también al Estado (Walsh, 2008a; 2008b; 2009a; 2009b).

La incorporación del término interculturalidad al ámbito del Estado como criterio de definición de políticas era el más claro registro de transformaciones significativas en la manera de interpretar y organizar las "diferencias culturales" hacia el interior de sus fronteras (Soria, 2010). La promoción de la interculturalidad irrumpía como un nuevo paradigma de relación social y cultural, o, como afirmaba Wright (1998), la cultura se politizaba en distintos campos y territorios de poder.

Los avances de política intercultural necesitaban ser ubicados en el contexto de las políticas de reconocimiento (que algunos formulaban en términos de políticas identitarias). El contexto internacional empujaba al reconocimiento de la diversidad cultural (Organización de las Naciones Unidas, 2007; Organización Internacional del Trabajo, 1989), y de esto se hacía especialmente eco en los "gobiernos progresistas" que iban emergiendo en la región. Durante este período, las minorías culturales, y en especial las latinoamericanas, despuntaron con movimientos sociales que demandaban de los Estados nacionales la autodeterminación, el reconocimiento, el respeto (e incluso la separación o un Estado propio), la participación política, el desarrollo con visión cultural, las autonomías territoriales y la representación parlamentaria, la garantía de derechos colectivos, políticas antidiscriminatorias, el reconocimiento de justicia propia (o ancestral), la educación en su propia lengua, etc. Con las políticas de reconocimiento, los grupos subordinados buscaban la aceptación — política o cultural- del grupo dominante; apuntando a la protección de los derechos básicos de los individuos como seres humanos (ideal de la dignidad) y al reconocimiento de las necesidades particulares de los individuos como miembros de grupos culturales específicos ${ }^{5}$. Por lo general, estas políticas públicas solían presentarse como superadoras de estrategias asimilacionistas e integracionistas, que habían sido los modelos para "incorporar" a los indígenas a patrones de modernidad nacional. Mostraban cómo los Gobiernos de algunos países

5 En contraposición a la política de reconocimiento está la política de la diferencia. En esta última, el grupo o individuo se enfoca en retener la propia identidad, más allá de la cuestión del reconocimiento, con el propósito de no ser asimilados en un cuerpo centrado en normativas y dictámenes, sino ser respetados como no asimilables. 
iban reformulando sus relaciones con los pueblos indígenas y ejecutaban políticas públicas "inclusivas", por ejemplo, para favorecer la presencia de jóvenes de estos pueblos en la universidad.

Durante los años en que desarrollaba la investigación, la inclusión y la interculturalidad fueron dos puntos centrales de la agenda políticoeducativa. Por eso se promovían políticas gubernamentales específicas para "grupos históricamente relegados", pero, también, alguna que otra privada, como en el caso de la congregación salesiana, que, a través de cupos y becas, facilitaban el acceso y la permanencia de estudiantes indígenas y afroecuatorianos en carreras profesionalizantes. Esta congregación católica llegó al país a fines del siglo XIX, y desde entonces sus tareas de evangelización y sus obras en distintos planos socioeducativos (desde escuelas hasta cooperativas de desarrollo económico) han tenido una destacada influencia.

Asimismo, existían posturas que denunciaban las políticas interculturales - y las prácticas y discursos que desplegaban - por considerarlas insertas en las lógicas del mercado capitalista, pero sin que llegaran a contribuir a la superación de condiciones de desigualdad y exclusión (Bazán, 2014; Benavides-Mora, 2008; Bertely, 2008; De Sousa-Santos, 2010; Dussel, 1991; 1994; Hinkelammert, 2001; Mignolo, 2008; 2010; Muyolema, 2001; Quijano, 2001; 2006; 2014, y otros). Desde estas perspectivas, la interculturalidad se presentaba como una ilusión colectiva que daba continuidad a las jerarquías coloniales y a la violencia simbólica ejercida sobre los indígenas (Patzi, 1999) o como una marca híbrida, una palabra-código en el contexto de globalización para designar mezcla, reciclaje de fragmentos de culturas e identidades que circulaban (Richard, 2012). Las críticas abarcaban las políticas educativas interculturales, porque los cupos no eran suficientes (De Souza-Lima, 2007) o porque muchas propuestas eran versiones light o neoliberales de la gestión de la diversidad; en definitiva, propuestas de "interculturalidad funcional" dirigidas a atenuar los costos que los estudiantes de origen indígena tenían que pagar para convertirse en "profesionales exitosos" y bien adaptados (Walsh, 2014a; 2014b). Otros denunciaban la falta de espacio para que los propios pueblos indígenas tomaran decisiones sobre la educación que querían y requerían (Dietz, Mendoza-Zuany \& Téllez-Galván, 2008).

Por último, es necesario explicitar que utilizo el concepto de reconocimiento en un doble sentido. Por un lado, desde el campo del derecho como reconocimiento político y sus consecuentes políticas de reconocimiento (Taylor, 1996); por otro, en un campo social más abarcador, dada la necesidad que todo sujeto tiene de reconocimiento para poder construir una identidad estable y plena con miras a la autorrealización (Honneth, 1996; 
1997) ${ }^{6}$. Honneth afirma que la vida social se cumple bajo el imperativo de un reconocimiento recíproco, ya que los sujetos solo pueden acceder a una autorrelación práctica si aprenden a concebirse a partir de la perspectiva normativa de sus compañeros de interacción, en tanto destinatarios sociales.

\section{Los talleres en la residencia estudiantil}

La Residencia Intercultural Don Bosco7, al sur de la ciudad de Quito, fue uno de los lugares en donde hice trabajo de campo desde mediados del 2013, con estadías regulares durante todo el 2014 e instancias más puntuales entre el 2015 y abril del 2016. En el momento de llegar, propuse a sus autoridades una serie de talleres ${ }^{8}$ para los jóvenes que quisieran participar libremente. Esto me permitió estar más tiempo con los estudiantes, profundizar mi acercamiento a ellos y ganar confianza; asimismo, me ayudó a distanciarme del rol de tutora o profesora de la universidad, en el que inicialmente me ubicaba el personal de la residencia.

El número de los estudiantes que participaba iba cambiando de semana a semana, algunas veces venían menos de diez y otras superaban los quince. En total, participaron veintidós estudiantes becados de distintas comunidades del Ecuador y de distintas carreras, como Gerencia y Liderazgo, Pedagogía, Biotecnología, Comunicación Social e Ingeniería. Al grupo de jóvenes becados se sumaron otros cuatro estudiantes de la misma universidad para cuestiones y momentos puntuales: una estudiante avanzada de la carrera de Filosofía, que estaba interesada en acompañarme para conocer el enfoque etnográfico, y que fue presentada como mi ayudante, y ya terminados los talleres y en plena producción del libro, otros tres estudiantes de la carrera de Comunicación, para tareas de fotografía, filmación y edición del material producido.

En las dos horas aproximadas que duraban los talleres, los estudiantes de la residencia se expresaban de distintas maneras, de modo que

6 Honneth (1996) explica las tres praxis necesarias para que se constituya el reconocimiento: las relaciones emocionales primarias, la praxis social del derecho y la de la solidaridad.

7 El nombre de Residencia Intercultural Don Bosco se había dado justamente en el año en que yo comencé el trabajo de campo. Previamente, ese mismo lugar era conocido como Hospedería Campesina, ya que albergaba a población indígena que llegaba a la ciudad buscando nuevas posibilidades de trabajo. Esta transformación demuestra un cambio en las funciones de este proyecto salesiano.

8 Los talleres fueron siete, y luego continuaron las reuniones para preparar el libro y el evento. 
produjeron dibujos y pinturas, relatos, dramatizaciones; elaboraron mapas; tomaron fotos, y cantaron y bailaron. Se abrían cada vez más al diálogo, compartían experiencias, pensamientos y sentimientos; así fueron hablando de sus vidas; sus familias; sus alegrías, miedos y tristezas; sus nostalgias y sueños; sus comunidades y pueblos; sus carreras; sus profesores y su estar en la ciudad, en la residencia salesiana y en la universidad.

Los talleres fueron una puerta que me permitió moverme con mayor libertad en la Resi (como los jóvenes la llamaban muchas veces) y compartir otros momentos y espacios, como salir juntos a algunos parques del barrio, recorrer uno de los campus de la universidad, acompañarlos a hacer algunas compras. Fue un período muy rico del trabajo de campo, porque el trabajo en colaboración con el grupo —en aquella primera entrada al campo-generó mayor cercanía y confianza con todos los que vivían y trabajaban en el lugar.

\section{iVamos a hacer un libro! Definiciones sobre el título}

La producción de los talleres fue tan abundante y rica que surgió la idea de mostrarla de alguna forma. Decidimos hacer una publicación con la colaboración de todos, usando algunos de los ejes trabajados en los talleres. Muchos de ellos expresaron inmediatamente motivación por la tarea: "Va a estar bueno, ivan a salir nuestras fotos!", "¿Vamos a poder poner nuestras historias y propuestas?", "iVamos a poder mostrar el libro en nuestras comunidades!, iqué todos sepan que podemos llegar a ser profesionales!".

Como yo trabajaba en la universidad salesiana y había hablado con algunas personas sobre mi investigación y mi interés de hacer parte de mi trabajo de campo en la residencia con estos jóvenes, fui, también, a plantear a las autoridades la posibilidad de la publicación y de contar con algunos fondos económicos disponibles para este propósito. Inmediatamente, hubo apertura, y se convino en hacer averiguaciones en la editorial universitaria. Yo iba contando al grupo sobre estas conversaciones, y una vez que tuve asegurados estos aspectos, les confirmé que podríamos hacer un libro y que había apoyo y dinero para ponerle color, fotos y dibujos. Esta noticia los alegró mucho.

Un día fui interpelada por los estudiantes de la residencia en un encuentro para avanzar con la preparación del libro. Yo había llevado unas fotocopias en las cuales tenía pasado en limpio la posible organización o estructura que podía tener el texto, y que habíamos conversado muy rápidamente la semana anterior. Les propuse pensar y definir juntos un título. En algún momento de ese encuentro, hablé de "estudiantes indígenas". 
Uno de los jóvenes rápidamente expresó: "No estamos de acuerdo con el título del libro. iLa palabra indígena no va, no, se ve mal, suena mal! iNosotros somos interculturales!". A John, se sumaron dos compañeras:

Magui: -Nosotros somos "pueblos originarios", shuar, waorani, panzaleos, quichuas.

John: - Nosotros somos "pueblos originarios". A mí me dijo un profesor del colegio que en realidad Colón iba a la India y llegó acá. Y bueno, nos pusieron ese nombre [suspira].

Lis: - Sí, es como que fue una equivocación, por error.

John: - Y quedó "indígena", pero nosotros somos "pueblos originarios". $Y$ hay muchos, no es todo igual.

A partir de ahí, surgieron alternativas al título. Algunos estudiantes decían sus ideas, y yo las iba escribiendo en un pizarrón que había en el salón en el que estábamos reunidos: "Estudiantes interculturales juntos por un mundo mejor", "Residentes interculturales universitarios. Un relato colectivo", "Formación intercultural", "Estudiantes interculturales en busca de la felicidad". En pocos minutos, todos se pusieron de acuerdo en que el término intercultural tenía que formar parte del título de una u otra manera; finalmente, fue seleccionado "Estudiantes interculturales en la universidad. Un relato colectivo" (notas de campo, 26 abril de 2014).

El rápido y espontáneo intercambio entre Magui, John y Lis me sorprendió y descolocó. John era de Bomboiza, estaba en $6^{\circ}$ semestre de la carrera de Gerencia y Liderazgo, era uno de los más antiguos en la residencia; Magui era de Zumbahua, también era una estudiante avanzada, y estaba en $5^{\circ}$ semestre de la misma carrera. Ella me había contado que en las últimas campañas electorales "había estado haciendo política" con su hermano, quién finamente salió elegido como vicepresidente de la Junta Parroquial. Lis, también de la misma carrera, había nacido en Taisha, y estaba en primer año. Ellos fueron los que tomaron la palabra y me encararon tocando un tema para nada menor.

El planteamiento de una denominación identitaria diferente a la que yo tenía en mente me desubicó. Algo no comprendí de lo que ellos me decían. Con los estudiantes había venido hablando del tema, y el grupo había mostrado una postura de aceptación y entusiasmo a la propuesta. ¿De dónde salía ahora ese "No estamos de acuerdo" que John había expresado en primera persona del plural, y al que Magui y Lis se adhirieron instantáneamente? ¿Habrían estado hablando antes del tema? ¿Transferían las 
connotaciones erróneas del término indio al de indígena? ¿Estaban vinculando pueblos originarios con la noción de interculturalidad como expresión novedosa que - más allá de los significados y sentidos que cada uno le estuviera dando- ellos también podían estar asumiendo y querían poner en el libro como forma de presentarse y posicionarse como grupo?

Más allá de mi perplejidad inicial, la tarde siguió su rumbo. No fue difícil encontrar un nuevo título que satisficiera al grupo. Los estudiantes proponían nuevos nombres. Yo dije lo del relato colectivo, y ellos estuvieron de acuerdo con esa parte. La elección se fue dando de forma participativa: opinaban, expresaban gustos, acuerdos o desacuerdos. La mayoría del grupo demostraba entusiasmo. Tomé el registro ese mismo día con la sensación de que algo bueno había pasado, aunque sin advertir — como mucho tiempo después lo haría - la relevancia de aquello. Lo que en aquel momento percibí era que a la oposición que habían planteado Lis, John y Magui muchos habían asentido con gestos o breves "claro" o "sí", y otros habían permanecido callados, o por lo menos yo no me había dado cuenta de qué pensaban, de si estaban o no de acuerdo. Sumado a esto, y a que había algo más que yo no lograba entender sobre el contenido mismo de lo que me dijeron, retomé días más tarde el asunto de manera casual. Así había quedado mi nota:

En el debate por el nombre del libro, no todos los estudiantes hablaron. Algunos permanecieron callados y por eso - en días posteriores y de forma más o menos directa - retomé el tema con un breve intercambio informal con algunas de las estudiantes. Una joven de Zumbahua me dio su opinión: "Es que no quieren que generalice a todos, pero, en mi punto de vista, nosotros ya somos conocidos como indígenas, a lo menos los de quichua que soy yo, pero no sé las otra chicas". Otra estudiante me dijo: "Nosotros sí nos reconocemos como indígenas, pero sí es mejor poner intercultural por algunos, para que entren todos" (cuaderno de campo, 5 de mayo de 2014).

Parecía ser, por lo que decían estas jóvenes, que algunos grupos étnicos eran conocidos y reconocidos, pero que otros no (o aún no); y que la denominación de interculturales abarcaría a todos, también a afroecuatorianos y a grupos más invisibilizados, menos conocidos o reconocidos. ¿Qué era lo que "sonaba mal"? ¿Nominaciones que ocultaban la diferencia cultural, la historia previa, las luchas, los sueños? ¿Sonaba a discriminación? ¿Sonaba poco moderno ante los nuevos discursos de interculturalidad? ¿"Sonaba mal" un poco por todo esto junto?

Fue mucho tiempo después que descubrí nuevos sentidos al episodio sobre la definición del título de la publicación. Si bien estos jóvenes habían 
migrado a la ciudad como "destinatarios o beneficiarios indígenas de políticas de inclusión", no solo ninguno de ellos me habló de inclusión, sino que tampoco aceptaban la categoría de indígenas, por el riesgo de ser usada como representación de la otredad desde la fijeza y los estereotipos que de modo ambivalente actúan en el discurso colonial, con poder discriminatorio (Bhabha, 2002). Ellos reconceptualizaban su denominación identitaria como interculturales y posicionaban fuertemente su rol como estudiantes. Definirse como jóvenes interculturales que migraron a la ciudad para estudiar en la universidad los ubicaba en un lugar muy distinto a ser "beneficiarios" o "destinatarios" de becas y cupos de grupos que eran clasificados con denominaciones que a veces sonaban feas, como me había interpelado Jhon. La nueva designación les permitió reconocerse a través de una categoría más propia del ámbito universitario: estudiantes interculturales, que a su vez los ubicaba en la nueva denominación que los salesianos le habían dado a la Residencia Intercultural como estudiantes.

La interculturalidad fue mostrada como denominación de identidad por estos jóvenes, despegándose de sistemas convencionales de clasificación: indios-no indios, indígenas-no indígenas, y emergiendo en un intersticio de agencia o, como explica Bhabha (2002), en un espacio "entre medio":

Estos espacios "entre-medio" proveen el terreno para elaborar estrategias de identidad (singular o comunitaria) que inician nuevos signos de identidad, y sitios innovadores de colaboración y cuestionamiento, en el acto de definir la idea misma de sociedad. Es en la emergencia de los intersticios (el solapamiento y el desplazamiento de los dominios de la diferencia) donde se negocian las experiencias intersubjetivas y colectivas de nacionalidad, interés comunitario o valor cultural (Bhabha, 2002, p. 18).

Los estudiantes pudieron hacer de ese lugar un espacio político de agencia entre el discurso hegemónico y el de la alteridad para construir una nueva enunciación. Bhabha (2002) afirma que en estos espacios de progreso se alzan identidades híbridas cuando la perspectiva de las minorías (los que se sitúan a medio camino entre la tradición y la modernidad, cuyas voces han sido soterradas por las voces dominantes) da cuenta de una "realidad Otra".

Estos jóvenes interlocutores, que eran ahora coautores, estaban construyendo un nuevo sentido para presentarse en el libro que estábamos planificando. La colaboración convirtió el espacio del trabajo de campo, entendido como de recolección de datos, en coconceptualización (Rappaport, 2007), al ser agenciado por los estudiantes como un lugar de enunciación desde lo intercultural, que permitía incluir a los diversos pueblos 
originarios que habían nombrado, a los afrodescendientes, a las jóvenes que se reconocían como indígenas y a los que sentían que "sonaba fea" esa denominación.

La definición que se dieron como sujetos ayuda a pensar en identidades que van mutando según sitios, roles, perspectivas futuras, relaciones con otros, elecciones particulares y reconocimiento recíproco. En las prácticas colaborativas que siguieron para avanzar con la preparación del libro emergieron decisiones del grupo en el mismo sentido.

\section{¿Qué entra en el libro? Organizar la publicación}

Mientras yo hacía consultas con las autoridades de la universidad y con responsables de la editorial universitaria sobre tiempos, formatos y posibilidades para la publicación, con los estudiantes íbamos conversando y diagramando el índice y la selección del material. Nos dimos cuenta de que algunas fotos que habíamos tomado en nuestros encuentros no tenían la calidad adecuada para que salieran bien impresas. También que teníamos videos, pero que no sabíamos cómo mostrarlos, y fue cuando pensamos en acompañar el libro con un material audiovisual. Definimos que podría ser un CD.

En ese momento, busqué la ayuda de otros tres estudiantes de la carrera de Comunicación para que pudieran ayudarnos con algunas fotos de mejor resolución y con grabaciones para armar el video del CD. Organizamos una jornada de fotos y de filmación en la residencia y otra en la universidad. Para el libro, usamos algunas fotos de las tomadas en los talleres y otras de aquel día de grabación. Las primeras habían sido tomadas mucho más espontáneamente durante el trabajo, la mayoría de las veces sin "posar".

Los estudiantes interculturales estuvieron entusiasmados y recibieron en la residencia a sus compañeros de Comunicación Social. Entre unos y otros definían tomas, espacios para sacarse fotos, eligiendo todo el tiempo qué mostrar y qué no. Recuerdo que cuando llegué ese sábado a la residencia con los estudiantes de Comunicación, algunas de las estudiantes mujeres me dijeron que se iban a "cambiar y arreglar". Regresaron con una vestimenta que las identificaba con su comunidad, amplias faldas y blusas bordadas, y se cambiaron sus zapatillas deportivas por zapatos de taco. Otra de las mujeres achuar se pintó la cara para salir en un video y las estudiantes afroecuatorianas se cambiaron con otros vestidos para filmar un trocito de una danza esmeraldeña. Ese día, también fuimos a un parque del barrio donde ellos solían pasear y al campus sur de la universidad, que estaba cerca de la residencia. En esos espacios posaban una y otra vez, y pedían y sugerían nuevas fotos. 
Las aulas y los patios fueron los lugares elegidos dentro de la universidad para sacar las fotos y filmar. Fotos en las que se viera que estudiaban y pequeñas filmaciones en las cuales ellos querían mostrarse jugando fútbol, explicando la experiencia de estar en Quito y estar estudiando para llegar a ser profesionales.

En los próximos encuentros, pero también por mail o en alguna visita que me hicieron en la universidad, los estudiantes interculturales fueron seleccionando el material de registro de los talleres y el contenido: fragmentos de unas autobiografías que habían escrito en uno de los talleres; las fotos que más les gustaban; algunos dibujos, escritos y narrativas; carteles escritos colectivamente, y videos. Todo con el propósito de mostrar quiénes eran ellos y por qué estaban en la universidad estudiando.

Hablamos sobre cómo hacer para mostrar dónde estaba la residencia, y decidimos incorporar un mapa en el libro. En la primera parte, yo escribiría cómo surgió el trabajo, enmarcándolo en la investigación, y, en la segunda, se presentarían los estudiantes becados contando cómo había sido su proceso de migrar y adaptarse a la ciudad y a la universidad; aspectos de su vida cotidiana; los sentires, percepciones y motivaciones que tenían como estudiantes de diferentes lugares geográficos; experiencias culturales y lenguas, y cómo era compartir la vida en una residencia estudiantil con el objetivo de seguir estudios profesionales.

En la primera parte del libro, también, escribió la estudiante que desempeñó el rol de asistente de investigación, relatando cómo el proceso la fue interpelando como parte del grupo. Para la segunda parte del texto, definimos cuatro puntos con los siguientes subtítulos: "Algo sobre nosotros", "La llegada a la universidad y los desafíos de adaptarse y estudiar", "Propuestas para la universidad que necesitamos" y "Mirando nuestro futuro". Las conclusiones fueron escritas por todos. Para la carátula optamos por fotos de algunos de sus rostros, teniendo en cuenta que hubiera mujeres y hombres, de la costa, de la sierra y del oriente ecuatoriano.

En algunos talleres y en muchas interacciones e intercambios que fui teniendo con los estudiantes, ellos me habían contado, también, dificultades, problemas, sufrimientos o temores, pero eran todos estos aspectos que "a usted le contamos o acá los decimos, pero no los ponga". En cambio, mostrar los esfuerzos que se hacían por estudiar, los proyectos y sueños futuros como profesionales que aportaran a sus familias y comunidades eran aspectos relevantes para integrar en la publicación. En el apartado sobre las propuestas a la universidad, ellos denunciaron situaciones en las que no se sintieron bien tratados, y brindaron ideas sobre tutorías, convivencias y encuentros con los compañeros, campañas de arte y cultura, y hasta mejoras para algunas carreras específicas. 
La decisión de ser coautores estaba clara para el grupo, pero se presentaron muchas resistencias a la hora de concretar aspectos para la edición del libro. Era la primera vez que en la editorial una profesora que estaba haciendo una investigación presentaba a un grupo de tantos estudiantes de grado como coautores: "Veintidós son muchos, no se puede poner". Palabras más o menos, eso era lo que se me decía una y otra vez. Tuve que hablar con el responsable final de la editorial y con el vicerrector para explicar y justificar por qué insistía en ese particular. Finalmente, la decisión fue que en la carátula iría mi nombre, y en los créditos el listado de todos los estudiantes autores y colaboradores (incluida la asistente de investigación). El tema de la autoría plural (Clifford, 1992) tenía evidentemente sus problemáticas a la hora del control editorial.

Hagamos una breve digresión para decir que en aquel momento las universidades ecuatorianas pasaban por tiempos de evaluación y que las publicaciones sumaban puntos para la acreditación institucional. Era un libro que, además, mostraba a la universidad con políticas concretas de inclusión y de trabajo con "grupos históricamente relegados". Por estos motivos, era una publicación que empezó a interesar a los que la conocían o habían oído hablar de ella.

Otra cuestión que conversé largamente con la persona encargada de la edición fue la de respetar la forma en que los estudiantes habían escrito. Fuimos y vinimos con este tema, ella hizo consultas a otras personas de la editorial y quedamos en que se corregirían las faltas ortográficas, pero no la forma en que se expresaban los estudiantes para narrar o explicar.

\section{La presentación pública del libro}

El libro quedó editado a todo color, con 127 páginas, y el CD se puso en la contracarátula interna, con imágenes, música, bailes, fragmentos de testimonios y entrevistas que fueron compiladas en un pequeño video por parte de los tres estudiantes de la carrera de Comunicación. El Departamento de Comunicación preparó la invitación, que circuló con anticipación en redes sociales, en la página oficial de la universidad, y llegó a los correos de profesores y del resto del personal universitario. Los estudiantes también se las hicieron llegar a sus familias. Se utilizó la misma portada del texto para armar la invitación. Por tanto, tampoco la invitación llevó el nombre de cada uno de los estudiantes, sino que quedó mi nombre como investigadora y ellos quedaron nombrados genéricamente como "estudiantes de la residencia". Que las autoridades de la universidad eligieran el Aula Magna destacaba de manera singular el evento, ya que no era un lugar usado para la presentación de libros. 
Preparamos el evento con anticipación junto con los jóvenes; ellos se organizaron en grupos y definieron actividades diferentes para que estuvieran representados los estudiantes de las tres regiones del Ecuador (la costa, la sierra y el oriente). Unos decidieron hablar, otros bailar y otros recitar. Una de las estudiantes saludó en quichua, otro compañero tradujo el saludo en castellano y prosiguió con un discurso, los del oriente realizaron un baile shuar, y una estudiante afroesmeraldeña declamó el poema "Canción del niño negro y del niño blanco", del ecuatoriano Nelson Estupiñán. Previamente, tuve que convencer al personal del Departamento de Comunicación y Cultura (que solía ocuparse de este tipo de eventos y presentaciones) para modificar un poco los protocolos comunes y que se pudiera hacer lo que habíamos pensado, de modo que el acto estuviera a cargo de los estudiantes interculturales.

Una vez más, medié sobre la forma en que los estudiantes irían vestidos ese día. "Deben ponerse sus trajes típicos" opinaron algunas personas que trabajaban en la residencia. Les expliqué que con los estudiantes habíamos conversado que cada uno elegiría cómo ir a la presentación. Así ocurrió finalmente. Los estudiantes de pueblos amazónicos y esmeraldeños se cambiaron de vestimenta luego de los bailes que representaron; no así algunas estudiantes de la sierra ecuatoriana, que permanecieron con sus faldas, sus blusas amplias y sus sombreros para las fotos y el almuerzo festivo.

Presentar la publicación en noviembre del 2014, y luego de más de un año de trabajo colectivo, fue muy importante y significativo para todo el grupo. El Aula Magna rebalsó de gente, de palabras de agradecimiento de autoridades y de los propios estudiantes. En la mesa directiva del Aula Magna de la Sede de Quito se sentaron el rector; la vicerrectora; el editor general de la editorial universitaria; la directora de la Carrera de Pedagogía (carrera en la que yo trabajaba); el director de la Pastoral Universitaria; el director del Centro de Investigación en Niñez, Adolescencia y Juventud, y yo. Los estudiantes de la residencia se ubicaron en lugares reservados en las primeras filas y pasaron al escenario cuando algunos de ellos intervinieron, destacando la contribución del libro desde distintas perspectivas. El director de Pastoral Universitaria argumentó con fuerza aquel día que la Universidad Politécnica Salesiana (UPS) tenía un camino recorrido en la interculturalidad, aunque el término era usado más cercanamente al discurso estatal, convergiendo con la apuesta constitucional ecuatoriana del Estado plurinacional. Él dijo:

La Universidad Politécnica Salesiana asume oficialmente, como parte de su visión institucional, la "interculturalidad". En el artículo cuatro de los Estatutos de la universidad leemos "Queremos ser una institución 
de Educación Superior de referencia en la búsqueda de la verdad y del desarrollo de la cultura, de la investigación científica y tecnológica, reconocida socialmente por su calidad académica, su responsabilidad social universitaria y por su capacidad de incidencia en el campo intercultural". Dentro de los objetivos que se plantea la Universidad Salesiana de manera explícita se señala: "Propiciar el diálogo entre las diversas culturas nacionales y desarrollar proyectos que favorezcan la interculturalidad del país" (discurso en evento de presentación del libro Jóvenes indígenas y afroecuatorianos en la universidad. Un relato colectivo de los sentidos del ser y estar en la universidad, 12 de noviembre de 2014).

Más adelante, hablaron dos estudiantes de la residencia, quienes agradecieron a la universidad la oportunidad de las becas para estudiar y valoraron el libro, en el que podían verse y mostrar lo alto que estaban llegando con tanto esfuerzo para estudiar. Una de ellas saludó en quichua e inmediatamente tradujo el saludo. A continuación, yo destaqué el rol de los estudiantes como coautores (Milstein, 2010) y conté la importancia de haber tejido juntos nuestras experiencias de vida y de vida académica e investigativa a partir de todo lo que había ocurrido en los talleres. Invité a todo el grupo de autores a subir al escenario. Ellos se mostraron emocionados, alegres, conmovidos, y recibieron un aplauso largo y entusiasta de parte de todo el auditorio. Posteriormente, se hizo un brindis con todos los presentes y un almuerzo para los autores, las autoridades y el personal de la residencia. Hubo gran cantidad de fotos y felicitaciones. La noticia fue recogida en varios boletines y publicaciones de los salesianos y de la universidad. Durante el receso por vacaciones de Navidad, los jóvenes llevaron el libro a sus comunidades, lo mostraron a sus familias, buscaron conseguir más ejemplares y me contaron emocionados las resonancias. Los estudiantes aportaban a las conclusiones del libro así:

A través de este libro las personas van a conocer a los distintos pueblos y culturas que estemos estudiando, porque piensan que es imposible que lleguemos. // Queremos decir que todo esto que hemos hecho es para demostrar la forma de vida de las diferentes culturas, sacando la cultura adelante, con diferentes ideologías, etnias, costumbres. Y es importante hacer conocer a todos. // Queremos que con este libro se familiaricen todos, porque hay que conocer, ya que uno aprende de los otros. // A mí me gustó todo esto que hicimos porque nos pudimos expresar porque a veces no sabemos con palabras. Este libro es como contar nuestra historia de todo nuestro proceso universitario. Hubo cosas buenas y malas, hubieron rechazos e inseguridad en la Carrera pero esas barreras que nos marcaron, han servido para salir adelante y descubrir lo que queríamos para nuestra vida profesional y para nuestros pueblos de dónde venimos. // iQueremos 
poder llevar este libro a nuestras comunidades y que también lo vean acá, en la ciudad porque estamos todos y todas las culturas hacen la "interculturalidad"! (Di Caudo et al., 2014, p. 112).

Para los jóvenes, este era un evento que los ubicaba en el centro de la escena como estudiantes interculturales, entre autoridades universitarias, profesores, compañeros, pares y familiares (aunque estos últimos no pudieron estar presentes debido a la distancia) y les permitía presentarse como coautores que tenían algo que decir, contar y mostrar en un libro. No solo eran beneficiarios de oportunidades de programas y de políticas educativas, sino que ellos, también, eran sujetos productores de conocimiento. Se mostraron como estudiantes interculturales enunciando y materializando procesos de reconocimiento propios y conflictivamente híbridos, como pudiera expresar Bhabha (2002). Las fachadas, actuaciones e idealizaciones (en términos de Goffman [2001]) incorporaban, ejemplificaban y se apropiaban de los sentidos y valores oficialmente acreditados de inclusión e interculturalidad desde el discurso estatal y desde el discurso misional de la universidad. Se mostraba e instalaba un reconocimiento (en sentido amplio del término) que cumplía con lo que los estudiantes habían dicho: "Aquí [refiriéndose al libro] estamos todos y todas las culturas hacen la interculturalidad" y lo que Mary me había expresado ese día: "No es imposible que los shuar [ni ningún otro estudiante intercultural] Ilegue a la universidad". Ahí estaban mostrando a todos que era posible y que, además, estaban permaneciendo en la universidad y produciendo conocimiento.

Todo el proceso demostró algo muy distinto a la inclusión intercultural, tantas veces entendida como política de cupos, becas y "políticas afirmativas de grupos relegados". Expuso la perspectiva que estos jóvenes tenían sobre ser estudiantes interculturales como un lugar de producción identitaria y desde un rol que los mostraba como productores de conocimiento: escribían, investigaban, publicaban un libro y preparaban un evento académico, nada menos que en el Aula Magna de la universidad.

Referirnos a inclusión intercultural y a estudiantes interculturales es algo distinto, con matices y contradicciones que yo misma no había advertido hasta que el proceso de investigación y de escritura etnográfica colaborativa me lo fue develando. iCuántas veces, desde que había comenzado a investigar el tema, recibía en entrevistas y en diversas interacciones durante el trabajo de campo el valor de la inclusión intercultural en la universidad; pero, al mismo tiempo, comentarios y afirmaciones descalificadoras de estos estudiantes: "No pueden, no saben, no van a tener éxito en la universidad porque no están preparados"! Asimismo, en forma simultánea, se 
desarrollaban muchos trabajos sobre los jóvenes indígenas que llegaban a la universidad. Muchísimos de ellos no los involucraban, sino que hablaban de o sobre ellos, pero no con ellos.

"Nosotros somos interculturales" fue un posicionamiento identitario fuerte, a partir del cual ellos transmitieron una determinada forma de ser considerados y reconocidos - y no solo visibilizados-, de conocerlos y comprenderlos, de escucharlos, trabajar y producir junto con ellos. En definitiva, no eran meros beneficiarios, sino sujetos con agencia, que como estudiantes podían compartir y construir conocimiento hablando, investigando, escribiendo, publicando y presentando un libro.

intercambio y en el trabajo que emprendimos como coautores de un libro. Que lo enunciaran me permitió advertir el distanciamiento con la inclusión intercultural pensada desde un enfoque de política pública y derecho que manejaban otros interlocutores del campo, como algunos salesianos, profesores, autoridades y agentes gubernamentales. La enunciación como estudiantes interculturales marcaba una situación de presentación hacia los otros y de interacción con los otros (Goffman, 2001), instalando un reconocimiento, un trato, una exigencia moral que condensaba sentidos identitarios y de reconocimiento recíproco.

El lugar de la política entramada con el lugar de lo político (Abéles, 2004) hacía el de la interculturalidad es, al mismo tiempo, un proyecto político y una conquista en permanente tensión relacional, en la cual, los jóvenes mostraron la importancia de visibilizar la diferencia como lugar potente 
de reconocimiento y agencia en el ámbito académico y la identidad, como recurso y derecho (Muñoz-Cruz, 2001). En la diferencia, este grupo (que comenzó siendo de colaboradores y terminó siendo de coautores) pudo construir un proceso de enunciación positivo de sus culturas, de sus historias y experiencias específicas y de sus identidades como jóvenes que migraban a la ciudad, estudiaban para ser profesionales, investigaban con una profesora, escribían un libro. Como explica Rappaport: "Lo que ocurre en el campo es crucial para la manera en que se conducen los trabajos en colaboración: mucho más que la recolección de datos, en el espacio del campo se está desplegando un proceso de interpretación colectiva" (2007, p. 203).

Tal vez podemos pensar que la residencia, un lugar que los acogía en la ciudad mientras estaban lejos de sus comunidades para estudiar en la universidad, se convirtió en un entre-lugar (Bhabha, 2002) a partir del trabajo etnográfico colaborativo. Un entre-lugar que permitió ciertos modos intersticiales de agencia para elaborar estrategias de subjetivación que dieron inicio a nuevas denominaciones identitarias, innovación y producción como estudiantes universitarios interculturales. Un entre-lugar entre sus comunidades y la ciudad, entre sus comunidades y la universidad, entre el colegio secundario y la educación superior como terrenos contradictorios y ambivalentes con posibilidad, justamente, tanto de articulaciones como de deconstrucciones, en un juego dialéctico de reconocimiento.

Los jóvenes convertían la residencia, la ciudad y la universidad en un espacio y en un tiempo distinto al de sus comunidades para desplegar sus agencias (y no solo para recibir "becas de inclusión"), desafiar de diferentes modos ciertas construcciones hegemónicas sobre lo indígena, los jóvenes del campo, los que no van a llegar a la universidad. Aprendían y realizaban ajustes constantes en los nuevos contextos cotidianos, negociaban representaciones sobre sí mismos en las relaciones sociales de las que eran parte. Vivían su cultura como una compleja trama de interacciones, en las cuales se daban dinámicas productivas y reproductivas al mismo tiempo (Barth, 1976; Briones, 1998; Ingold, 2008; Kropff, 2011; Ramos \& Kropff, 2004; Sahlins, 1997), poniendo en jaque ciertas categorías con las cuales otros sujetos (y yo misma como investigadora) a veces describían sus procesos de migración y estudio, usando términos tales como éxito, fracaso, adaptación, shock cultural, etc.

\section{Conclusiones}

Trabajar colaborativamente con este grupo de estudiantes en la etnografía, escribir y publicar con ellos, me permitió entender la importancia y los sentidos que ellos le daban a presentarse como estudiantes 
interculturales del nivel superior; al modo en que ellos querían mostrarse, ser, hacer, decir, escribir y producir ante los demás, y la forma de incorporar y asimilar otros marcos y discursos: políticos, socioculturales y educativos sobre la interculturalidad, la inclusión y el reconocimiento.

Las prácticas colaborativas que compartimos me descubrieron las identidades dinámicas y flexibles de estos jóvenes que permanentemente interactuaban con otros sujetos en contextos sociales y culturales específicos, que destacaban la importancia de visibilizar la diferencia como lugar potente de reconocimiento, según situaciones, entornos y acontecimientos. Por eso es que se puede comprender la recreación de significados cuando una estudiante se presentaba como la única shuar en la universidad y otros, como estudiantes interculturales. Mostrarse como actores únicos en un lugar (la universidad) o como grupos particulares (estudiantes interculturales en la ciudad) demostró que los lugares y los roles o acciones que se realizaban daban significado identitario. Situarse como estudiantes interculturales creaba un sentido positivo de sí mismos que les permitía convertirse en agentes de su propio desarrollo y resistir imágenes estereotipadas, folclorizadas, racistas o colonializadas sobre las identidades étnicas o sobre "grupos vulnerables y relegados" que reciben beneficios.

Este artículo expuso que la etnografía es un producto de la interacción, por tanto, es siempre dialógica. Como explica Johannes Fabian (2007), hacer etnografía es intentar producir, representar y re-presentar el conocimiento de otros(s) que son nuestros interlocutores. Por eso gran parte del conocimiento cultural es performativo, representado en y mediado por situaciones (como fueron los talleres y la producción del libro), que podemos desencadenar, pero no controlar (Fabian, 2007). Este grupo de estudiantes con quienes trabajé crearon el significado y le dieron sentido al encuentro intercultural. A partir de mi trabajo como investigadora hubiera alcanzado a entender un poco más los sentidos sobre la inclusión intercultural desde distintos grupos, discursos y políticas. Solo junto al grupo de jóvenes, y a partir de las relaciones intersubjetivas, pude comprender que ser estudiante intercultural era algo muy distinto. Al quedar perpleja en la definición del título del libro, al escribir con ellos, al seleccionar material y producir datos, al esbozar un índice y preparar un evento, pude no solo obtener nueva información, sino descubrir nuevos sentidos y perspectivas que redefinieron la investigación, enriquecieron el proceso y produjeron conocimiento. En el caso de esta investigación (de la cual acá comparto el hecho puntual de la producción del libro), pude argumentar cómo las relaciones interculturales ayudaban a resistir ciertas posiciones de identidades marginalizadas atribuidas a los estudiantes indígenas y afroecuatorianos, y estudiar la inclusión intercultural como una producción 
sociocultural (Willis, 1993) ${ }^{9}$ que implica procesos de trabajo activo, real, colectivo y creativo, que conlleva la inversión de recursos de muchos agentes, generando la comprensión de sí mismos en su propio mundo cultural.

La interculturalidad implica — pero al mismo tiempo excede — la valoración y respeto de lo diverso o el mero reconocimiento de derechos; tiene una profunda importancia social y política, y posibilita relaciones e intercambios estableciendo un principio de obligatoriedad mutua, que asume igualitariamente las responsabilidades que supuso, en este caso, investigar, escribir y presentar un libro entre un grupo de jóvenes y una investigadora. Como planteó ampliamente Mignolo (2002; 2006; 2008), la interculturalidad no es solo el estar juntos, sino aceptar la diversidad del ser en sus necesidades, opiniones, deseos, conocimientos, perspectivas, etc. Lo intercultural interpela a todos, e implica la descolonización de las relaciones en los espacios cotidianos de convivencia social y política; supone un diálogo entre diversos agentes para construir elementos comunes y producir un conocimiento mutuo. Significa romper con nociones hegemónicas, totalitarias, discriminatorias, racistas o segregacionistas, y pensar en nuevas praxis relacionales, descolonizando las relaciones entre los individuos y los pueblos, y sus maneras de construir identidades.

En el trabajo que produjimos con los jóvenes, la interculturalidad no fue un hecho existente, sino que se fue construyendo. En ese proceso, la denominación de estudiantes interculturales fue un hito que permitió repensar la noción de inclusión o el planteo de la interculturalidad desde el discurso estatal, y abrir una perspectiva de interculturalidad como horizonte (que esta experiencia solo esbozó). Los jóvenes me propusieron una transformación, y ese viraje tenía que ver con intervenir en paridad y reconociendo la diferencia de poder que tenían ellos como estudiantes becados con la profesora que estaba trabajando en esos talleres para investigar y producir un libro.

Sabemos y admitimos que las relaciones interculturales se estructuran históricamente bajo la sombra de las relaciones de poder y que apuntan claramente a reconocer, tolerar o incorporar lo diferente dentro de una matriz colonial y estructuras establecidas. Pero creemos que también pueden dar origen a entramados heterogéneas y discontinuos en entre-medios o zonas fronterizas e implosionar desde la diferencia en las estructuras coloniales

9 Para Willis, los actos culturales están intrínsecamente motivados con aspectos de la construcción de la identidad, y esas prácticas culturales producen algo que no estaba allí, al menos no totalmente o de la misma manera: "Esta identidad debe ser viable y creíble, en el sentido de saber 'cómo seguir avanzando' en el mundo social y también para ganar aceptación y respeto por los demás, incluso en la lucha por la existencia material, buscar y encontrar la dignidad y el reconocimiento" (Pimenta, 2005). 
del poder. Un reto, una propuesta, un proceso, un proyecto pueden ser intentos por reconceptualizar y re-fundar estructuras que logran poner en escena y en relación equitativa lógicas, prácticas y modos culturales diversos de pensar, actuar y vivir, tal como fue la escritura, la edición y la presentación del libro en el Aula Magna.

Experiencias como estas, muy particulares pero significativas, ayudan a demostrar que la etnografía en colaboración en ámbitos educativos puede convertirse no solo en un terreno fértil —no solo para la investigación, porque incide, reorienta o transforma los proyectos y la forma de construir conocimiento- sino en un lugar posible de encuentro y enunciación para articular decisiones aún más trascendentes en este horizonte intercultural. Estas decisiones requieren de esfuerzos y toma de posiciones ético-políticas y de compromisos educativos con las minorías.

\section{Sobre la autora}

María Verónica di Caudo-Villoslada es doctora en Ciencias de la Educación de la Universidad Nacional de Córdoba, Argentina. Magíster en Ciencias Sociales y Humanidades; licenciada y profesora en Ciencias de la Educación, y profesora de educación preescolar. Se dedica a la formación docente. Sus temas de interés se relacionan con el método etnográfico, la educación y la interculturalidad.

\section{Referencias}

Abéles, M. (2004). La antropología política: nuevos objetivos, nuevos objetos. En A. Marquina-Espinosa (Coord.), El ayer y el hoy: lecturas de antropología política (pp. 51-72) (Vol. 1, Hacia el futuro). Madrid: Universidad Nacional de Educación a Distancia.

Altmann, P. (2013). Interculturalidad y plurinacionalidad como conceptos decoloniales-colonialidad y discursos del movimiento indígena en el Ecuador. En Actas del XV Encuentro de Latinoamericanistas Españoles, noviembre de 2012 (pp. 131-138). Madrid, España: Trama CEEIB. Recuperado de https:// halshs.archives-ouvertes.fr/halshs-00873607/document

Aponte-Hernández, E. (2008). Desigualdad, inclusión y equidad en la educación superior en América Latina y el Caribe: tendencias y escenario alternativo en el horizonte 2021. En A. L. Gazzola y A. Didriksson (Eds.), Tendencias de la educación superior en América Latina y el Caribe (pp. 113-154). Caracas: IESALC-Unesco.

Barth, F. (Comp.). (1976). Los grupos étnicos y sus fronteras. La organización social de las diferencias culturales. México: FCE.

Bazán, M. D. (2014). Interculturalidad ineoliberal? o Neoliberalismno intercultural. Revista del Cisen Tramas/Maepova, 3, 15-39. Recuperado de http://ppct. caicyt.gov.ar/index.php/cisen/article/viewFile/5467/10497 
Benavides-Mora, C. A. (2008). Democratizar va más allá de acceder a la educación. Pensamiento propio y alternativa al desarrollo. En G. Dietz, R. Mendoza-Zuany, G. Rosa \& S. Téllez-Galván (Eds.), Multiculturalismo, educación intercultural y derechos indígenas en las Américas (pp. 245-266). Ecuador: Abya-Yala.

Bertely, M. (2008). Educación intercultural para la ciudadanía y la democracia activa y solidaria. Una crítica de la otra educación al multiculturalismo neoliberal y comunitarista. En G. Dietz, R. Mendoza-Zuany, G. Rosa \& S. Téllez-Galván (Eds.), Multiculturalismo, educación intercultural y derechos indígenas en las Américas (pp. 267-302). Ecuador: Abya-Yala.

Bhabha, H. K. ([1984] 2002). El lugar de la cultura. Buenos Aires: Manantial.

Briones, C. (1998). La alteridad del Cuarto Mundo. Una deconstrucción antropológica de la diferencia. Buenos Aires: Colihue.

Castro-Freitas A. \& Harder E. (2013). Novos processos educativos no ensino superior: produção intelectual de jovens indígenas no contexto dos Grupos PET-Programa de Educação Tutorial, Conexão de Saberes, Ministério da Educação/MEC. Disertación presentada en GT 03 de X Reunión de Antropología del Mercosur Situar, Actuar e Imaginar Antropologías desde el Cono Sur. Córdoba: Universidad Nacional de Córdoba.

Clifford, J. (1992). Sobre la autoridad etnográfica. En C. Reynoso (Comp.), El surgimiento de la antropología posmoderna (pp. 147-170). Barcelona: Gedisa.

Chiroleu, A. (2009). La inclusión en la educación superior como tema de la agenda de gobierno en América Latina. Una reflexión sobre las propuestas del CRES/2008. Universidades, 40(enero-marzo), 19-28. Recuperado de https:// www.redalyc.org/pdf/373/37313028003.pdf

Chiroleu, A. (2013). ¿Ampliación de las oportunidades en la educación superior o democratización? Cuatro experiencias en América Latina. Actualidades Investigativas en Educación, 13(3), 1-24. Recuperado de https://www. redalyc.org/pdf/447/44729878024.pdf

De Souza-Lima, A. C. (2007). Educación superior para indígenas en el Brasil: más allá del sistema de cupos. En S. García \& M. Paladino, Educación escolar indígena. Investigaciones antropológicas en Brasil y Argentina (pp. 63-75). Argentina: Antropofagia.

De Sousa-Santos, B. (2010). Descolonizar el saber, reinventar el poder. Portugal: Trilce.

Di Caudo, M. V. et al. (2014). Estudiantes interculturales en la universidad: un relato colectivo desde Ecuador. Quito: Abya-Yala Universitaria.

Fabian, J. (2007). Memory against Culture: Arguments and Reminders. Durham, NC: Duke University Press.

García, S. \& Paladino, M. (Comp.). (2007). Educación escolar indígena. Investigaciones antropológicas en Brasil y Argentina. Argentina: Antropofagia.

García, S. \& Paladino, M. (2011). La escolarización en los pueblos indígenas americanos. Impactos y desafíos. Ecuador: Abya-Yala-Universidad Politécnica Salesiana.

Goffman, E. ([1959] 2001). La presentación de la persona en la vida cotidiana. Buenos Aires: Amorrortu. 
Guber R., Milstein D. \& Schiavoni, L. (2014). La reflexividad o el análisis de datos. Tres antropólogas de campo. En R. Guber (Comp.), Prácticas etnográficas. Ejercicios de reflexividad de antropólogas de campo (pp. 41-63). Argentina: Miño y Dávila-IDES.

Hinkelammert, F. (2001). El nihilismo al desnudo. Los tiempos de la globalización. Santiago de Chile: Lom.

Honneth, A. (1996). Reconocimiento y obligaciones morales. Revista Internacional de Filosofía Política, 8, 5-17. Recuperado de https://dialnet.unirioja.es/ servlet/articulo?codigo $=2704755$

Honneth, A. (1997). La lucha por el reconocimiento. Por una gramática moral de los conflictos sociales. Barcelona: Crítica.

Dietz, G. (2012). Reflexividad y diálogo en etnografía colaborativa: el acompañamiento etnográfico de una institución educativa "intercultural" mexicana. Revista de Antropología Social, 21, 63-91. doi: 10.5209/rev_RASO.2012. v21.40050

Dietz, G., Mendoza-Zuany, R. G. \& Téllez-Galván, S. (Eds.). (2008). Multiculturalismo, educación intercultural y derechos indígenas en las Américas. Ecuador: Abya-Yala.

Dussel, E. (1991). Introducción a la filosofía de la liberación. Bogotá: Nueva América.

Dussel, E. (1994). El encubrimiento del otro. Hacia el origen del mito de la modernidad. La Paz: Plura-Centro de Información para el Desarrollo.

Ingold, T. (2008). Tres en uno: cómo disolver las distinciones entre mente, cuerpo y cultura. En Tomas Sánchez-Criado (Ed.), Tecnogénesis. La construcción técnica de las ecologías humanas (Vol. 2, pp. 1-33). Madrid: AIBR.

Kropff, L. (2011). Los jóvenes mapuche en Argentina: entre el circuito punk y las recuperaciones de tierras. Alteridades, 21(42), 77-89.

Maldonado, K. A. (Coord.). (2011). Interculturalidad y diversidad. Ecuador: Universidad Andina Simón Bolívar, Corporación Editora Nacional, Biblioteca General de Cultura.

Mignolo, W. (2002). Las geopolíticas del conocimiento y colonialidad del poder. Entrevista a Walter Mignolo. En C. Walsh, F. Schiwy \& S. Castro-Gómez (Eds.), Indisciplinar las ciencias sociales. Geopolíticas del conocimiento y colonialidad del poder. Perspectivas desde lo andino (pp. 17-44). Quito: UASB/Abya Yala.

Mignolo, W. (2006). El desprendimiento: pensamiento crítico y giro decolonial. En Interculturalidad, descolonización del estado y de conocimiento (pp. 9-20). Buenos Aires: Del Signo.

Mignolo, W. (2008). La opción descolonial. Letral, 1. Recuperado de https:// revistaseug.ugr.es/index.php/letral/article/view/3555

Mignolo, W. (2010). Desobediencia epistémica: retórica de la modernidad, lógica de la colonialidad y gramática de la descolonialidad. Buenos Aires: Ediciones del Signo.

Milstein, D. (2010). Escribir Con niñ@s: una posibilidad de coautoría en la investigación etnográfica. Revista Reflexão e Ação, 18(2), 65-91. Recuperado de https://online.unisc.br/seer/index.php/reflex/article/view/1510

Miranda, E. M. (2013). Políticas de inclusión en la educación superior en Argentina (2003-2012). VII Encuentro Nacional y IV Latinoamericano: La Universidad como Objeto de Investigación. Universidad Nacional de San Luis. 
Miranda, E. M. (Coord.). (2015). Democratización de la educación superior. Una mirada desde el Mercosur. A cuatrocientos años de la universidad en la región. Córdoba-Argentina: Narvaja.

Muñoz-Cruz, H. (2001). Trayectorias de las políticas de educación indígena en México. En H. Muñoz-Cruz et al., De prácticas y ficciones comunicativas y cognitivas en educación básica (pp. 433-494). México: UAM.

Muyolema, A. (2001). De la cuestión indígena a lo indígena como cuestionamiento. Hacia una crítica del latinoamericanismo, el indigenismo y el mestiz(o)aje. En I. Rodríguez (Ed.), Convergencia de tiempos: estudios subalternos/contextos latinoamericanos. Estado, cultura y subalternidad (pp. 327-364). Amsterdam/Atlanta, GA: Rodopi.

Organización de las Naciones Unidas (ONU). (2007). Declaración de las Naciones Unidas sobre los derechos de los pueblos indígenas. Recuperado de https:// www.un.org/development/desa/indigenous-peoples-es/declaracion-sobrelos-derechos-de-los-pueblos-indigenas.html

Organización Internacional del Trabajo (OIT). (1989). Convenio 169 de la OIT sobre pueblos indígenas y tribales. Recuperado de https://www.ilo.org/dyn/ normlex/es/f?p=NORMLEXPUB:12100:0::NO::P12100_ILO_CODE:C169

Ossola, M. M. (2010). Pueblos indígenas y educación superior. Reflexiones a partir de una experiencia de jóvenes wichí en la Universidad Nacional de Salta. Revista ISEES, 8. Recuperado de https://dialnet.unirioja.es/servlet/ articulo?codigo $=3777545$

Ossola, M. M. (2013). Jóvenes indígenas en la frontera: relaciones entre etnicidad, escolaridad y territorialidad. Revista Latinoamericana de Ciencias Sociales, Niñez y Juventud, 11(2), 547-562. Recuperado de http://www.scielo.org. co/pdf/rlcs/v11n2/v11n2a07.pdf

Ossola M. M. \& Paladino, M. (2016). Pueblos indígenas y educación superior en la Argentina: debates emergentes. Revista del Cisen Tramas/Maepova, 4(1), 57-77. Recuperado de http://ppct.caicyt.gov.ar/index.php/cisen/article/ view/8732

Patzi, F. (1999). Etnofagia estatal. Modernas formas de violencia simbólica (una aproximación al análisis de la reforma educativa). Bulletin de I'Institut Français d'Études Andines, 28(3). Recuperado de https://flacsoandes.edu. ec/web/imagesFTP/1289406868.La_Virgen_de_la_Dolorosa..._Gioconda_ Herrera.pdf

Pimenta, M. M. (2005). Entrevista com Paul Willis. Tempo Social, 17(2), 323-333. Recuperado de http://dx.doi.org/10.1590/S0103-20702005000200014

Quijano, A. (2001). Colonialidad, poder, cultura y conocimiento en América Latina. En W. Mignolo (Comp.), Capitalismo y geopolítica del conocimiento. El eurocentrismo y la filosofía de la liberación en el debate intelectual contemporáneo (pp. 117-131). Buenos Aires: Signo.

Quijano, A. (2006). El movimiento indígena y las cuestiones pendientes en América Latina. Argumentos, 19(50), 51-77 Recuperado de http://www.redalyc. org/articulo.oa?id $=59501903$

Quijano, A. (2014). Colonialidad del poder y clasificación social. En A. Quijano, Cuestiones y horizontes. De la dependencia histórico-estructural a la colonialidad/pescolonialidad del Poder (pp. 285-330). Buenos Aires: Clacso. 
Ramos, A. \& Kropff, L. (2004). Esa es mi historia. Memoria y narrativas del yo entre los mapuches. En B. Dávilo et al., (Coords.), Territorio, memoria y relato en la construcción de identidades colectivas (pp. 167-172). Rosario: UNR.

Rappaport, J. (2007). Más allá de la escritura: la epistemología de la etnografía en colaboración. Revista Colombiana de Antropología, 43, 197-229. Recuperado de http://www.humanas.unal.edu.co/colantropos/files/9114/ 7414/9089/Mas_alla_de_la_escritura_Rappaport.pdf

Richard, N. (2012). Localidades del saber: ubicación, contextos y traducción. En Colonialidad/decolonialidad del poder/saber. Miradas desde el Sur (pp. 99-106). Valdivia: Ediciones Universidad Austral de Chile-Clacso. Recuperado de http://www.biblioteca.clacso.edu.ar/ar/libros/coedicion/richard.pdf

Rosso, L. (2016). Pueblos indígenas y educación superior: indagaciones y experiencias en Argentina y Brasil. Revista del Instituto de Investigaciones en Educación, 7(8).

Sahlins, M. (1997). "O Pessimismo sentimental" e a experiencia etnográfica: por que a cultura nao é um "objeto em via de extinção". Mana. Estudos de Antropología Social, 3(1 y 2), 41-75 y 103-150.

Soria, A. S. (2010). Interculturalidad y educación en Argentina: los alcances del "reconocimiento". Andamios 7(13), 167-184. Recuperado de http://www. scielo.org. $\mathrm{mx} /$ scielo.php?script=sci_arttext\&pid=S1870-00632010000 200008

Taylor, C. (1996). Identidad y reconocimiento. Revista Internacional de Filosofía Política, 7, 10-19. Recuperado de https://dialnet.unirioja.es/servlet/ articulo?codigo $=2704736$

Walsh, C. (2008a). Interculturalidad crítica. Pedagogía de-colonial. En W. Villa y A. Grueso (Comps.), Diversidad, interculturalidad y construcción de ciudad. Bogotá: Universidad Pedagógica Nacional-Secretaría de Gobierno-Secretaría de Cultura.

Walsh, C. (2008b). Interculturalidad y plurinacionalidad: elementos para el debate constituyente. Quito: Universidad Andina Simón Bolívar.

Walsh, C. (2009a). Interculturalidad crítica y pedagogía de-colonial: apuestas (des) el in-surgir, re-insurgir y re-vivir. En P. Medina-Melgarejo (Coord.), Educación intercultural en América Latina. Memorias, horizontes históricos y disyuntivas políticas. México: UPN-Plaza y Valdés.

Walsh, C. (2009b). Interculturalidad, Estado, sociedad. Luchas (de)coloniales de nuestra época. Ecuador: Universidad Andina Simón Bolívar y Abya-Yala.

Walsh, C. (2014a). Decolonialidad, interculturalidad, vida desde el Abya-Yalaandino. Notas pedagógicas y senti-pensantes. En M. Borsani y P. Quintero (Comps.), Los desafíos decoloniales de nuestros días: pensar en colectivo. Neuquén: Educo, Editorial Universitaria, Universidad Nacional del Comahue.

Walsh, C. (2014b). Notas pedagógicas desde las grietas decoloniales. En Hemispheric Institute, 1(11).

Willis, P. (1993). Producción cultural no es lo mismo que reproducción cultural, que a su vez no es lo mismo que reproducción social, que tampoco es lo mismo que reproducción. En H. M. Velasco, A. Díaz de Rada \& F. J. García-Castaño (Eds.), Lecturas de antropología para educadores (pp. 431-461). Madrid: Trotta.

Wright, S. (1998). La politización de la cultura. Anthropology Today, 14(1). Recuperado de http://polsocytrabiigg.sociales.uba.ar/wp-content/uploads/ sites/152/2014/03/SUSAN_WRIGHT.pdf 